\title{
Rokitansky diverticulum with esophageo-spinal fistula leading to infective spondylodisciitis - A case report and review of literature
}

\section{ASHISH KUKREJA}

Manipal Hospital

\section{Balamurugan Thirugnanam}

Manipal Hospital

Seema Janardhan

Manipal Hospital

D Sreenivasa

Manipal Hospital

Thomas Joseph Kishen ( $\nabla$ thomas.kishen@manipalhospitals.com )

Manipal Hospital https://orcid.org/0000-0001-8467-5467

\section{Case Report}

Keywords: Rokitansky diverticulum, infective spondylodiscitis, thoracic vertebrae, mid-esophageal diverticulum

Posted Date: June 7th, 2021

DOl: https://doi.org/10.21203/rs.3.rs-564345/v1

License: (c) (i) This work is licensed under a Creative Commons Attribution 4.0 International License. Read Full License 


\section{Abstract}

Background-Infective thoracic spondylodiscitis secondary to spontaneous perforation of the esophageal diverticulum is a rare condition.

Case Report- A 56-year-old lady with cystic lung disease and pulmonary arterial hypertension of nine years duration and progressive dysphagia for two years was diagnosed with mid-esophageal diverticulum five months prior to presentation. The lady presented with infrascapular chest wall pain of one month's duration and dyspnoea and wheezing of 15 days duration. Imaging showed a midesophageal diverticulum at T4-T5 level with a sinus tract extending to the T2-T3 disc, reduced T2-T3 disc height with endplate irregularities, and contrast enhancement of T2-T5 vertebral bodies suggestive of spondylodiscitis. Although a percutaneous vertebral biopsy was inconclusive, the blood culture grew Streptococcus Pseudoporcinus. The esophageal diverticulum was managed with an endoluminal stent and the infective spondylodisciitis was managed with an extended course of antibiotics led to the healing of both lesions.

Conclusions- A Rokitansky mid-esophageal diverticulum with esophageo-spinal fistula causing infective spondylodisciitis is a rare condition. A combined management of the leaking esophageal diverticulum using an esophageal endoluminal metallic stent and an extended course of antibiotics to treat the infective spondylodisciitis led to a good outcome.

\section{Introduction}

Esophageal diverticulum, a saclike projection involving the layers of the esophageal wall, with a prevalence less than $1 \%$ of the general population and $1-3 \%$ of those presenting with dysphagia [1], occurs in all ages but is typically diagnosed in the elderly [1]. Although most esophageal diverticula are asymptomatic [2], some present with dysphagia, regurgitation, aspiration pneumonia, weight loss, heart burn, chest pain and vomiting [2]. Long standing inflammation can lead to perforation, bleeding, formation of abscesses, strictures or obstruction [3], esophagobronchial fistulas and acute mediastinitis [4]. Enlarging esophageal diverticula occupy the prevertebral space posterior to esophagus and any perforation or leak can lead to direct spread of GI microbes into the prevertebral space leading to spondylodiscitis and spinal epidural abscess [5].

In this report, we highlight the clinical features, imaging characteristics and management of leaking midesophageal diverticulum (Rokitansky diverticulum) communicating with the T2-T3 intervertebral disc space causing infective spondylodisciitis in a 56-year-old lady.

\section{Case Report}

A 56-year-old lady presented with bilateral infrascapular chest wall pain of one month duration and dyspnea and wheezing in the last 15 days. The pain was constant, aggravated by movements, without any radiation or numbness or weakness in extremities and the bowel and bladder function was intact. 
Spinal tenderness was absent and neurological examination was normal. Post-prandial heaviness in the chest, retrosternal burning and sensation of food stuck in the esophagus had been present for the preceding four years, progressive dysphagia (liquid > solid) for two years and she was diagnosed to have a mid-esophageal diverticulum approximately five months ago. Other medical co-morbidities included Cystic Lung Disease and Pulmonary Arterial Hypertension for nine years and hypertension for four years. Thoracic HRCT with oral contrast (Fig. 1) revealed a thoracic esophageal diverticulum at T4-T5 level with a linear tract of contrast coursing posteriorly into the T2-T3 disc space and T4 to T6 block vertebrae. A contrast MRI scan (Fig. 2) revealed reduced T2-T3 disc height with end plate irregularity, marrow oedema and uniform contrast enhancement of T2-T5 vertebral bodies suggestive of spondylodiscitis. A sinus track was identified from the esophagus tracking up to T2-T3 disc, with associated enhancing paravertebral soft tissue swelling/thickening and a small epidural collection causing mild cord compression at T2-T3 level. No cord edema or enhancement was noted.

Blood tests revealed WBC count $=7630 /$ cu.mm (Neutrophils $80.1 \%$, CRP $=3.53 \mathrm{mg} / \mathrm{l}, \mathrm{ESR}=48 \mathrm{~mm} / \mathrm{hour}$ and the blood culture grew Streptococcus Pesudoporcinus sensitive to Levofloxacin, Linezolid and Clindamycin. A CT guided vertebral biopsy (T2-T3) did not reveal any organisms on aerobic culture, GeneXpert for tuberculosis was negative and histopathological examination was inconclusive. A six weeks course of IV and oral Linezolid was initiated based on the blood culture reports.

A self-expandable metallic stent (SEMS) with stent fix ovesco clip was deployed to bypass the esophageal diverticulum and aid in the healing of the leak. A thoracic HRCT performed a month after stent deployment (Fig. 3) revealed contrast leakage along the upper end of the stent with posterior outpouching of the contrast into the diverticulum, while the sinus from the apex of this outpouching (which was present in earlier scan) was not opacified. A repeat scan after a ten-day trial of Ryles-tube feeding did not show any improvement and hence an esophago-gastro-duodenoscopy (OGD) and ReSEMS was performed one month after the primary stent placement. RT feeding was continued and an Oral Gastrograffin study performed three weeks after the second stent placement did not show no contrast leak. The stents were eventually removed after four months (after stenting) and follow up MRI scan of the thoracic spine (Fig. 4) obtained at this stage revealed thickening of the esophageal wall which was more pronounced on the posterolateral aspect at T3-T4 level with healing of the track and resolution of infective spondylodisciitis. At the six-month mark, the back pain had resolved completely and normal diet was reasonably well tolerated albeit with mild dysphagia.

\section{Discussion}

Esophageal diverticula could be either true diverticula (involving all the layers of the esophagus) or false diverticula (involving only the mucosal and submucosal layers only), pulsion diverticula (resulting from increased intraluminal pressure due to esophageal dysmotility leading to esophageal wall herniation in an area of weakness) or traction diverticula (wherein mediastinal inflammation adheres and pulls on the esophageal wall from outside causing a defect or diverticula). Based on the anatomic location, esophageal diverticula are further divided into three types namely [6]; (1) Zenker's diverticulum at the 
pharyngoesophageal junction (pulsion or false diverticula occurring in the Killians triangle), (2) Rokitansky diverticulum or mid-esophageal diverticulum which are true diverticula arising either due to traction or pulsion, and (3) epiphrenic diverticulum within $10 \mathrm{~cm}$ above the gastro-esophageal junction (pulsion or false diverticula that may result from increased lower esophageal sphincter pressure e.g. in achalasia).

Rokitansky or mid-esophageal diverticula were historically considered to be traction diverticula secondary to mediastinal inflammation from granulomatous infections like tuberculosis [7] and sarcoidosis [8] in the mediastinal lymph nodes causing local traction on the esophageal wall. However, recent studies have shown that a majority of mid-esophageal diverticula are pulsion diverticula secondary to motility disorders $[9,10,11,12,13]$. In addition, tuberculosis which was one of the primary causes of traction diverticula, is in decline in the Western world. Although most patients with esophageal diverticula are asymptomatic, some present with dysphagia, regurgitation, aspiration pneumonia, weight loss, heart burn, chest pain and vomiting. Long standing inflammation can lead to a full thickness erosion of the esophageal wall leading to esophagobronchial fistulas, mediastinitis [4] and any perforation or leak can lead to direct spread of GI microbes into the prevertebral space potentially leading to spondylodiscitis or spinal epidural abscess [13].

Esophageal diverticulum requires a thorough work-up including an esophagogram (to rule out mechanical obstruction), manometry (to rule out motility disorders), pH manometry (to rule our GERD) and endoscopy (to rule out mucosal lesions like neoplasms and ulcers). The treatment of esophageal diverticula is based on the pathophysiology and natural history of the disease: (a) asymptomatic diverticula do not need a specific treatment, (b) small diverticula may be left in place and not resected, (c) medium-size diverticula may be either treated by diverticulectomy, diverticulopexy, or esophagodiverticulostomy in case of pharyngoesophageal diverticula, (d) resection is probably the ideal therapy for larger diverticula, and (e) a myotomy should always be included to the procedure [2]. Minimally invasive procedures like video-assisted thoracoscopic surgery, laparoscopy and combined video-assisted thoracoscopic surgery and laparoscopy to perform a diverticulectomy and myotomy have been shown to be safe, successful [14] with reduced postoperative morbidity compared with the open thoracotomy approach [1]. Freeman has shown excellent outcomes following the deployment of esophageal stents for esophageal perforation, fistula, or anastomotic leak [15].

Spinal infection has been reported following iatrogenic esophageal injuries resulting from endoscopic management of Zenker's diverticulum [16, 17], upper GI endoscopic procedures [18], esophagectomy surgery [19], concurrent chemotherapy and radiotherapy [20], stenting of esophageal strictures [21], accidental esophageal injuries while eating fish [22] and chronic esophageal perforation [23]. Esophageal injuries have also been reported following anterior cervical spine surgery leading to infective spondylitis and spinal wound infection $(0.3-0.9 \%)[24,25,26]$.

A 56-year-old gentleman developed pyogenic cervical spondylitis four months after nasogastric feeding for a severe head injury. He was also found to have a Zenker's diverticulum. The spinal infection healed 
after a combination of surgical repair of the diverticulum and course of antibiotics [27]. Another 69-yearold lady who presented with scapular pain was diagnosed an esophageal diverticulum with fistula and T2-T3 spondylodisciitis. The patient refused an esophageal surgery and subsequently developed altered sensorium and encephalitis and became ventilator dependent [28].

The "classic triad" of localized back pain, progressive neurologic deficit, and fever in the diagnosis of spinal epidural abscess occurs only in $37 \%$ of patients [29], temperature above $37.5^{\circ} \mathrm{C}$ in $13-68 \%$ [30,31], neurological symptoms in $33 \%[30,31]$, constitutional symptoms (anorexia, nausea, vomiting and weight loss) in 5-50\% [31, 32], leukocytosis (> 11500/cumm) in 34-65\% and elevated ESR $(70 \mathrm{~mm} / \mathrm{hr})$ in $72 \%$ of patients [30,31]. However, the time to diagnosis of spondylodisciitis and epidural abscess is an independent risk factor for the development of adverse outcomes (1.4 months versus 2.1 months) [33] and a delay in diagnosis usually varies from 1 to 6 months [30,34]. Hence a strong index of suspicion is necessary to make an early diagnosis of infective spondylodisciitis and prevent a poor outcome.

The patient discussed in this report was admitted with infrascapular back pain without any neurological symptoms/signs, fever, elevated blood counts or inflammatory markers. However, the CT scan revealed an esophageal diverticulum with an esophago-spinal fistula and presence of contrast in the T2-T3 disc space. An MRI scan with contrast revealed reduced T2-T3 disc height with end plate and marrow oedema, uniform contrast enhancement of T2-T4 vertebral bodies and a small epidural collection suggestive of an infective spondylodisciitis. Although a CT guided percutaneous needle biopsy did not reveal the infective organism, a blood culture grew Streptococcus Pseudoporcinus which is a facultative Gram-positive coccus characterized by a large zone of beta-haemolysis. In the absence of spinal instability and symptomatic cord compression, it was decided to manage the spinal infection with appropriate antibiotics (based on sensitivity studies) and treat the esophageal diverticulum simultaneously. The patient's medical co-morbidities precluded an esophageal diverticulum repair surgery and hence deployment of an endoluminal self-expanding metallic stent was considered. Fortunately, a combination of esophageal stenting and extended course of antibiotics led to healing of the infective spondylodisciitis and correction of the leaking diverticulum.

\section{Conclusion}

A Rokitansky mid-esophageal diverticulum with esophago-spinal fistula causing infective spondylodisciitis is a rare condition. The patient discussed in this report went on to have a good outcome following a combined management of the leaking esophageal diverticulum using an esophageal endoluminal metallic stent and an extended course of oral antibiotics to treat the infective spondylodisciitis.

\section{Declarations}

We kindly thank all the colleagues working in various departments who helped us in carrying 
out this study.

Funding: No funding sources

Conflict of interest: None declared

Ethics approval- Ethical approval obtained from the institution from which the case is reported.

Consent to participate: Informed consent was obtained from all individual participants included in the study.

Consent to publish: The participant has consented to the submission of the case report to the journal.

Availability of data and material: Data is transparent and accurate.

Author contributions: All authors contributed to the study conception and design.

\section{References}

1. Onwugbufor MT, Obirieze AC, Ortega G, Allen D, Cornwell EE 3rd, \& Fullum TM. Surgical management of esophageal diverticulum: a review of the Nationwide Inpatient Sample database. J Surg Res. 2013;184(1):120-5. https://doi.org/10.1016/j.jss.2013.05.036.

2. Herbella FA, Patti MG. Modern pathophysiology and treatment of esophageal diverticula. Langenbecks Arch Surg. 2012;397(1):29-35. https://doi.org/10.1007/s00423-011-0843-2.

3. Feagans J, Raskin J. Historical Perspectives and the Spectrum of Diverticular Disease. J Clin Gastroenterol. 2011;45:3-6. 10.1097/MCG.0b013e31820ca671.

4. Roh S, Matveeva Y, Keech J, Parekh K, Arshava E. Diverticulosis and its complications in the foregut and small bowel. Curr Chall Thorac Surg. 2020. http://dx.doi.org/10.21037/ccts-20-62.

5. Ferreira LE, Simmons DT, Baron TH. Zenker's diverticula: pathophysiology, clinical presentation, and flexible endoscopic management. DIS ESOPHAGUS. 2008;21(1):1-8. https://doi.org/10.1111/j.14422050.2007.00795.x.

6. Carrère N, Pradère B. Diverticules de l'oesophage [Esophageal diverticula]. J Chir (Paris). 2004;141(2):85-92. https://doi.org/10.1016/s0021-7697(04)95575-5.

7. Ikeda Y. Traction mid-esophageal diverticulum associated with Pott's spinal caries. Dig Endosc. 2010;22(2):158-9. https://doi.org/10.1111/j.1443-1661.2010.00950.x.

8. Guirguis S, Azeez S, Amer S. Sarcoidosis Causing Mid-Esophageal Traction Diverticulum. ACG Case Rep J. 2016;3(4):e175. https://doi.org/10.14309/crj.2016.148.

9. Fernando HC, Luketich JD, Samphire J, Alvelo-Rivera M, Christie NA, Buenaventura PO, Landreneau RJ. Minimally invasive operation for esophageal diverticula. Ann Thorac Surg. 2005;80(6):2076-80. https://doi.org/10.1016/j.athoracsur.2005.06.007. 
10. Schima W, Schober E, Stacher G, Franz P, Uranitsch K, Pokieser P, Wenzl E, Resch A, Herold CJ. Association of midoesophageal diverticula with oesophageal motor disorders. Videofluoroscopy and manometry. Acta radiol. 1997;38(1):108-14. https://doi.org/10.1080/02841859709171252.

11. Hoghooghi D, Coakley FV, Breiman RS, Qayyum A, Yeh BM. Frequency and etiology of midesophageal diverticula at barium esophagography. Clin Imaging. 2006;30(4):245-7. https://doi.org/10.1016/j.clinimag.2006.02.002.

12. Nascimento FA, Lemme EM, Costa MM. Esophageal diverticula: pathogenesis, clinical aspects, and natural history. Dysphagia. 2006;21(3):198-205. https://doi.org/10.1007/s00455-006-9028-5.

13. Mercantini P, Virgilio E, Petrucciani N, Pardi M, Sebastiani S, Sagnotta A, Sforza N, Ziparo V. Giant midthoracic pulsion diverticulum of the esophagus. Am Surg. 2010;76(7):782-4. https://doi.org/10.1177/000313481007600744.

14. Macke RA, Luketich JD, Pennathur A, Bianco V, Awais O, Gooding WE, Christie NA, Schuchert MJ, Nason KS, Levy RM. Thoracic Esophageal Diverticula: A 15-Year Experience of Minimally Invasive Surgical Management. Ann Thorac Surg. 2015;100(5):1795-802. https://doi.org/10.1016/j.athoracsur.2015.04.122.

15. Freeman RK, Ascioti AJ. Esophageal stent placement for the treatment of perforation, fistula, or anastomotic leak. Semin Thorac Cardiovasc Surg. 2011;23(2):154-8. https://doi.org/10.1053/j.semtcvs.2011.08.005.

16. Ying J, Pei S, Su L, Wen T, Lv Y, Ruan D. Successful Conservative Management of Delayed Cervical Spondylodiscitis with Epidural Abscess Caused by Esophageal Diverticulitis: A Case Report and Review of Literature. World Neurosurg. 2018;118:250-60. https://doi.org/10.1016/j.wneu.2018.05.207.

17. Bonaddio V, Herman Z, Armstrong J, Kepler C, Molter M. Vague neck pain following a gastrointestinal procedure: a rare case presentation of vertebral osteomyelitis and cervical epidural abscess. Spinal Cord Ser Cases. 2020;6(1):40. https://doi.org/10.1038/s41394-020-0290-9.

18. Chen Y, Kim BJ, Lee SH, Hu SS. High thoracic spinal infection following upper gastrointestinal workup. J Clin Neurosci. 2007;14(11):1132-5. https://doi.org/10.1016/j.jocn.2006.02.023.

19. Mecklenburg I, Probst A, Messmann H. Esophagospinal fistula with spondylodiscitis and meningitis after esophagectomy with gastric pull-up. J Gastrointest Surg. 2008;12(2):394-5. https://doi.org/10.1007/s11605-007-0363-0.

20. Cordero-Jiménez A, Tenor-Serrano R, Muñoz-Palza C, Solano-Romero JR. Fístula esófagoespondilorraquídea en paciente tratado con radioterapia y quimioterapia [Spinal-esophageal fistula in a patient treated with concurrent chemotherapy and radiotherapy]. Acta Otorrinolaringol Esp (English Edition). 2012;63(3):241-3. https://doi.org/10.1016/j.otorri.2011.01.006.

21. Li CY, Chen WC, Yang SH, Lee YC. A rare complication of esophageal stent: spinal epidural abscess. Ann Thorac Surg. 2009;88(5):1700-2. https://doi.org/10.1016/j.athoracsur.2009.02.079.

22. Lehman CR, Deckey JE, Hu SS. Eikenella corrodens vertebral osteomyelitis secondary to direct inoculation: a case report. Spine (Phila Pa 1976). 2000;25(9):1185-7. 
https://doi.org/10.1097/00007632-200005010-00022.

23. Sreedharan L, Lakshmanan P, Shenfine J, Gibson MJ, Griffin SM. Thoracic vertebral osteomyelitis secondary to chronic esophageal perforation. Spine J. 2009;9(4):e1-5.

https://doi.org/10.1016/j.spinee.2008.05.010.

24. Korovessis P, Repantis T, Vitsas V, Vardakastanis K. Cervical spondylodiscitis associated with oesophageal perforation: a rare complication after anterior cervical fusion. Eur J Orthop Surg Traumatol. 2013;23(Suppl 2):159-63. https://doi.org/10.1007/s00590-012-1092-y.

25. Lee TS, Appelbaum EN, Sheen D, Han R, Wie B. (2019). Esophageal Perforation due to Anterior Cervical Spine Hardware Placement: Case Series. Int J Otolaryngol, 2019, 7682654. https://doi.org/10.1155/2019/7682654.

26. Epstein NE. A Review of Complication Rates for Anterior Cervical Diskectomy and Fusion (ACDF). Surg Neurol Int. 2019;10:100. https://doi.org/10.25259/SNI-191-2019.

27. Frot-Martin B, Carlier RY, Morand-Blot V, Faye A, Bernard L, Vallée C. Zenker's diverticulum associated with multilevel cervical osteomyelitis. Spine (Phila Pa 1976). 2001;26(9):E193-7. https://doi.org/10.1097/00007632-200105010-00020.

28. Lee JH, Kim E, Choi YH. Encephalitis as a complication of a spinal-esophageal fistula due to discitis. Clin Case Rep. 2019;7(11):2190-3. https://doi.org/10.1002/ccr3.2471.

29. Rigamonti D, Liem L, Sampath P, Knoller N, Namaguchi Y, Schreibman DL, Sloan MA, Wolf A, Zeidman S. Spinal epidural abscess: contemporary trends in etiology, evaluation, and management. Surg Neurol. 1999;52(2):189-97. https://doi.org/10.1016/s0090-3019(99)00055-5.

30. Butler JS, Shelly MJ, Timlin M, Powderly WG, O'Byrne JM. Nontuberculous pyogenic spinal infection in adults: a 12-year experience from a tertiary referral center. Spine (Phila Pa 1976). 2006;31(23):2695-700. https://doi.org/10.1097/01.brs.0000244662.78725.37.

31. Hopkinson N, Stevenson J, Benjamin S. A case ascertainment study of septic discitis: clinical, microbiological and radiological features. QJM. 2001;94(9):465-70. https://doi.org/10.1093/qjmed/94.9.465.

32. Jensen AG, Espersen F, Skinhøj P, Frimodt-Møller N. Bacteremic Staphylococcus aureus spondylitis. Arch Intern Med. 1998;158(5):509-17. https://doi.org/10.1001/archinte.158.5.509.

33. McHenry MC, Easley KA, Locker GA. Vertebral osteomyelitis: long-term outcome for 253 patients from 7 Cleveland-area hospitals. Clin Infect Dis. 2002;34(10):1342-50. https://doi.org/10.1086/340102.

34. Sobottke R, Seifert H, Fätkenheuer G, Schmidt M, Gossmann A, Eysel P. Current diagnosis and treatment of spondylodiscitis. Dtsch Arztebl Int. 2008;105(10):181-7. https://doi.org/10.3238/arztebl.2008.0181.

\section{Figures}




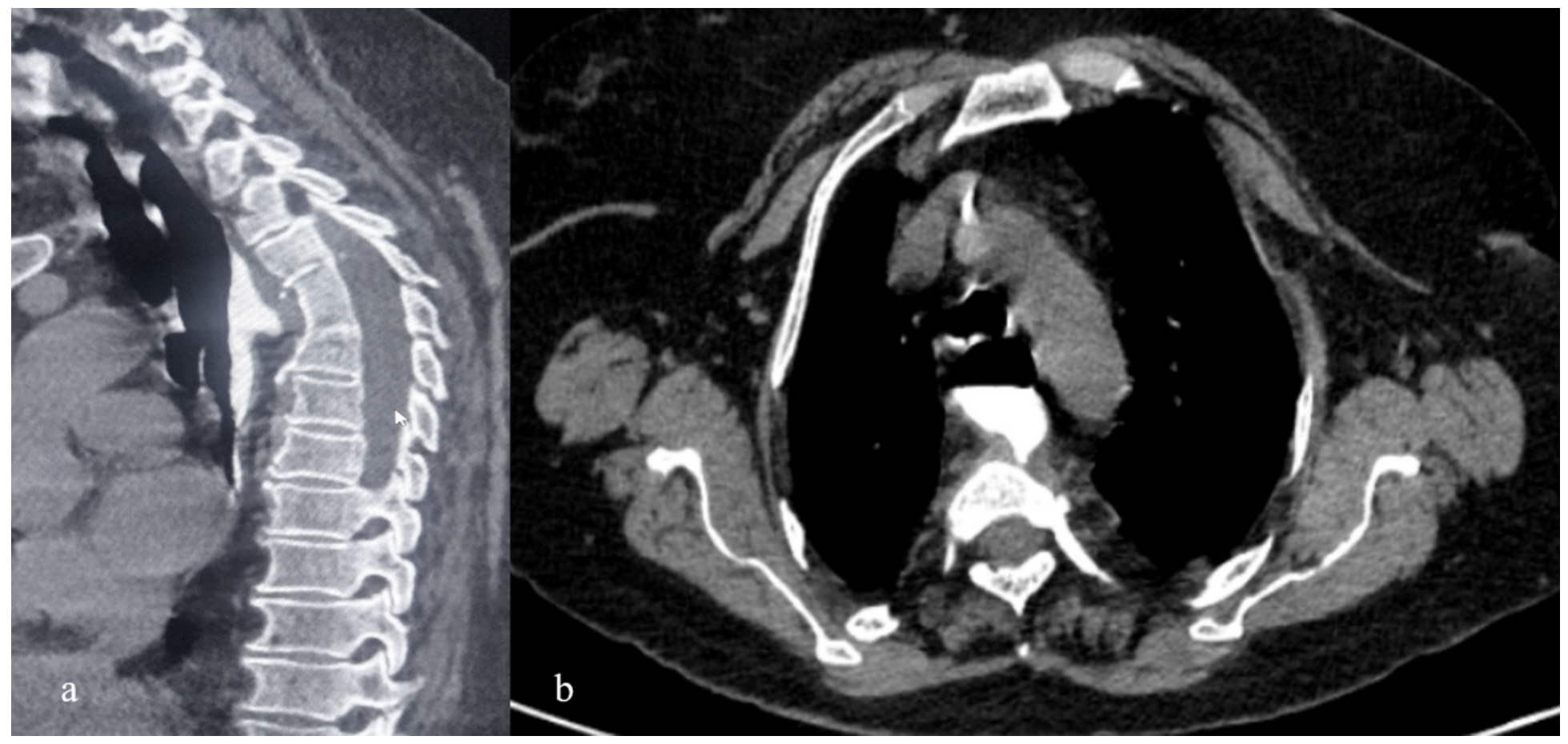

\section{Figure 1}

a post-contrast sagittal section and Fig. 1b post-contrast axial section of HRCT Thorax with Oral Contrast showing sinus tract of contrast from esophageal diverticulum tracking into the T2-T3 disc space

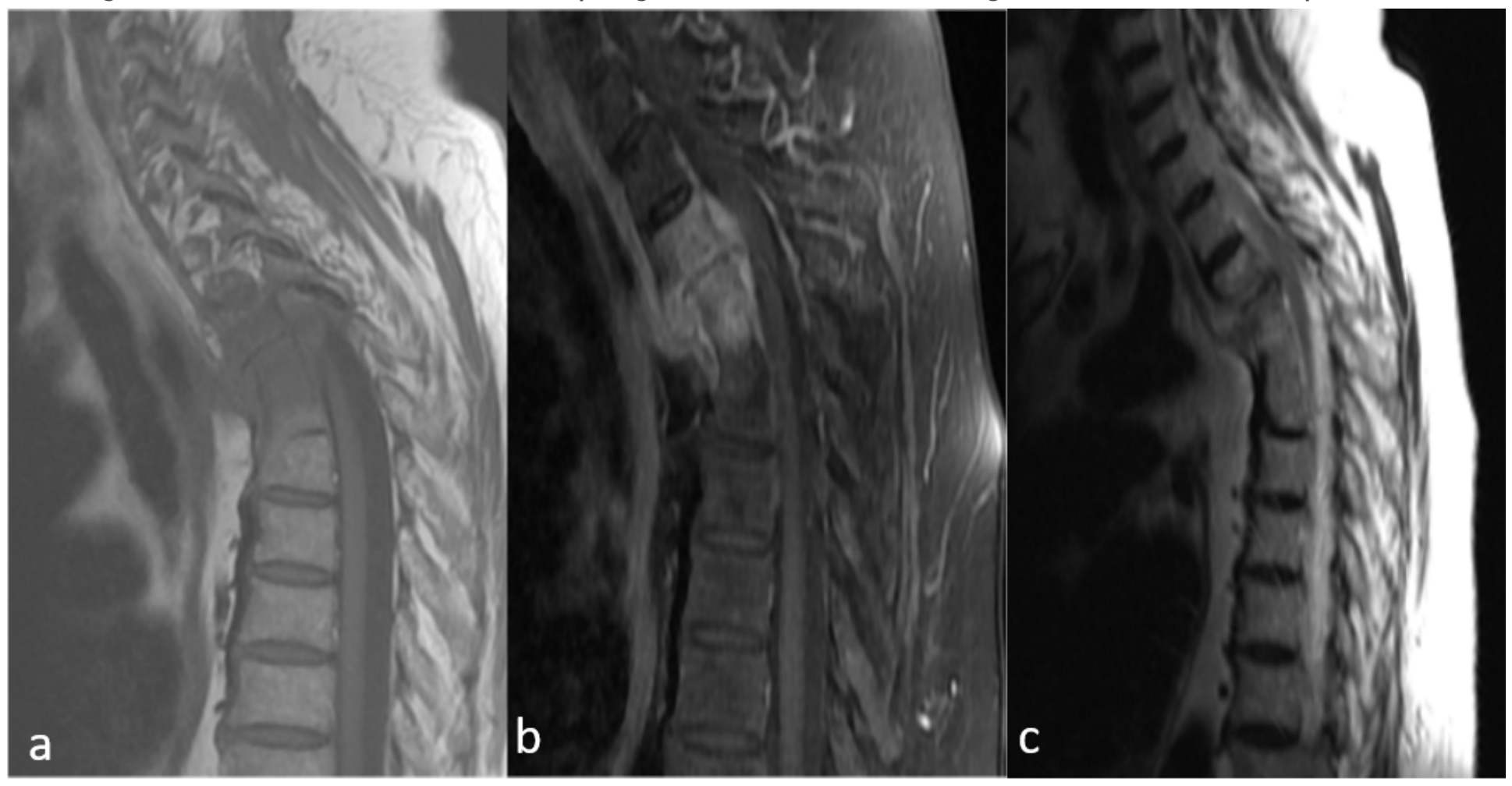

Figure 2 
a sagittal T1-weighted MRI section, Fig. 2b sagittal contrast T1-weighted MRI section and Figure 2c sagittal T2-weighted MRI section, reveals reduced T2-T3 disc height with contrast enhancement of T2-T5 vertebral bodies and enhancing of paravertebral soft tissue with a small epidural collection with no cord changes

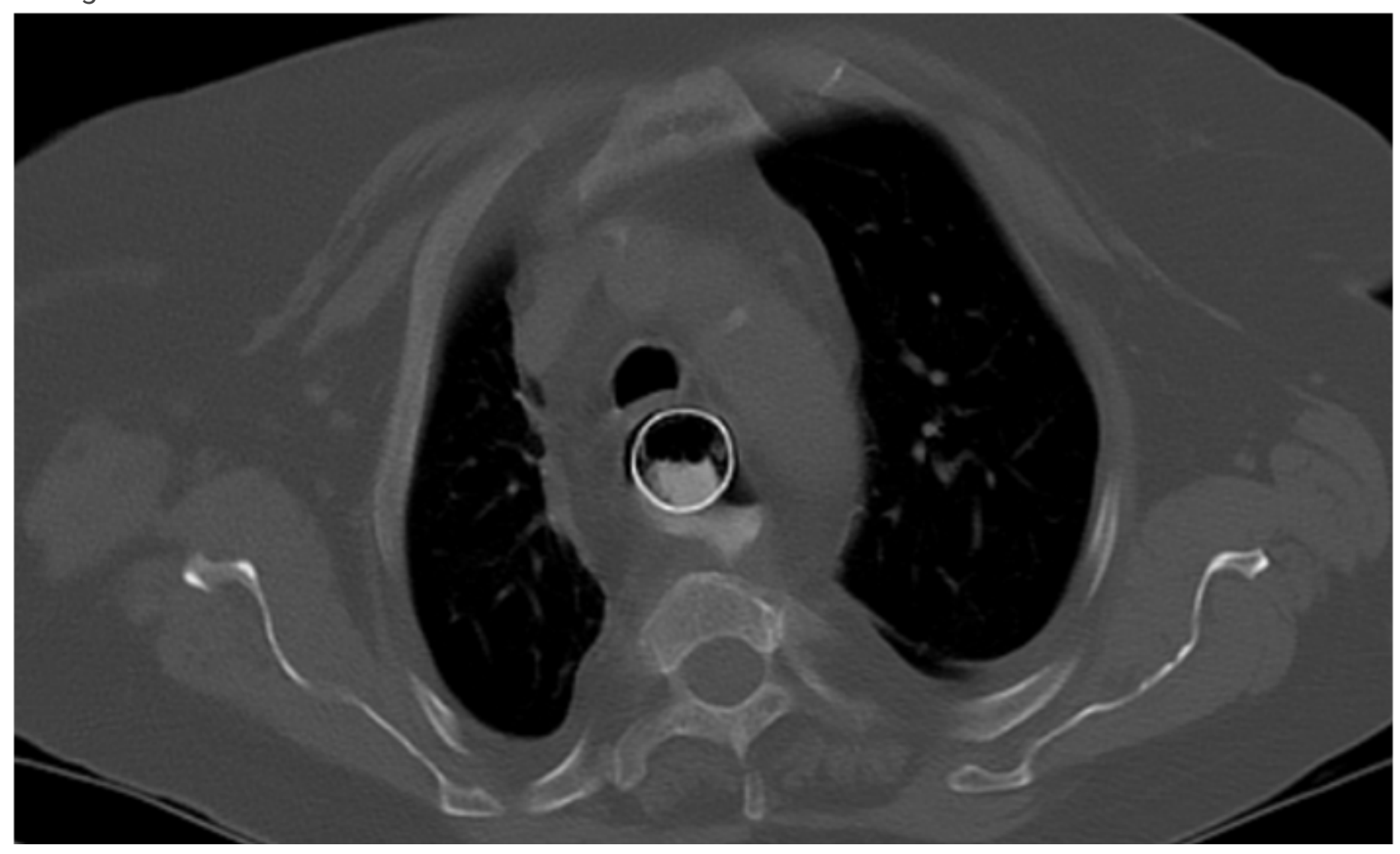

\section{Figure 3}

HRCT performed post stenting show posterior outpouching of the contrast into the diverticulum and the sinus from the apex of this outpouching into the prevertebral space 


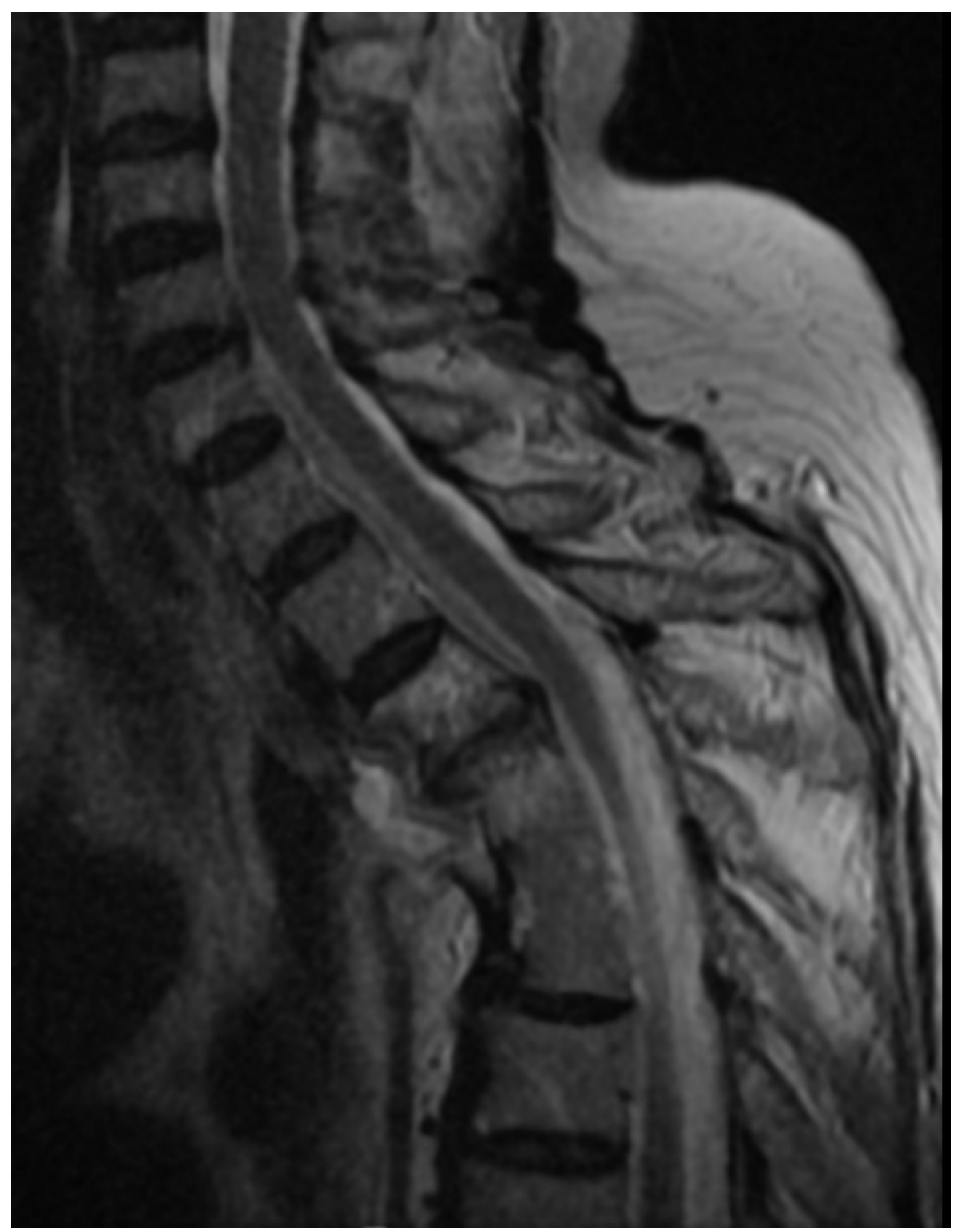

Figure 4

Follow-up MRI shows thickening of the oesophageal wall on the posterolateral aspect at the T3-T4 level with the healing of the tract and the spondylodiscitis

\section{Supplementary Files}

This is a list of supplementary files associated with this preprint. Click to download.

- CAREchecklist.docx 